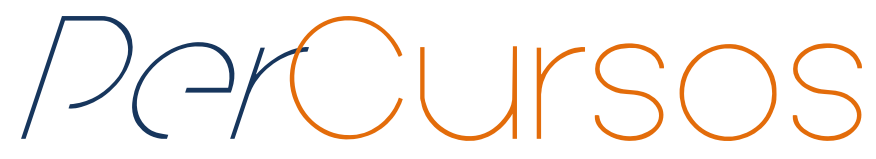

\title{
Vida e morte: a educação com arte. Um projeto do PIBID de Psicologia no Ensino Médio ${ }^{1}$
}

\begin{abstract}
Resumo
O artigo em questão é resultado das atividades desenvolvidas na disciplina eletiva de Filosofia em uma escola estadual de Goiás intitulada Vida e Morte: o que a arte tem a nos dizer sobre isso? Essa disciplina fez parte das atividades desenvolvidas pelo subprojeto de Psicologia do Programa Institucional de Bolsas de Iniciação à Docência (PIBID) da Universidade Federal de Goiás (UFG). Esse subprojeto tem como objetivo discutir e refletir temas da Psicologia com os alunos do Ensino Médio, a fim de contribuir com uma formação mais reflexiva e crítica dos mesmos. Essa disciplina visava fomentar discussões acerca de temas angulares da vida humana com apoio nas bases da Psicanálise e da expressão artística. Buscou-se demonstrar como a utilização da arte enquanto metodologia e recurso didático foram de fundamental importância para o ensino de Psicologia para adolescentes. Além de destacar a importância de ser reservado um espaço na escola para se falar sobre vida, morte e afetos e sobre como a Psicologia se insere nesse campo.
\end{abstract}

Palavras-chave: PIBID; Arte; Adolescência; Psicologia; Educação.

\author{
Jordana de Castro Balduino \\ Doutora em Educação pela \\ Universidade de Barcelona. \\ Professora da Universidade \\ Federal de Goiás - UFG. \\ Brasil
}

jordanabalduino@gmail.com

Luelí Nogueira Duarte e Silva

Doutora em Educação pela

Universidade Federal de Goiás -

UFG. Professora da Universidade Federal de Goiás - UFG. Brasil

lueliduarte1963@gmail.com

\section{Caroline Pereira Machado}

Graduanda em Psicologia na

Universidade Federal de Goiás -

UFG.

Brasil

carolinecpmachado@gmail.com

\section{Rosana Ferrari Pandim Lisboa Teixeira \\ Graduanda em Psicologia pela Universidade Federal de Goiás - UFG. Brasil \\ rosanaferrarip@gmail.com}

\footnotetext{
${ }^{1}$ Subprojeto integrante do projeto institucional da Universidade Federal de Goiás do Programa Institucional de Bolsas de Iniciação a Docência - PIBID, iniciativa da Coordenação de Aperfeiçoamento de Pessoal de Nível Superior - CAPES/MEC.
} 


\title{
Life and death: education with art in high school. The Psychology's PIBID project in High School
}

\begin{abstract}
The article is the result of a Psychology course named Life and Death: what art can tell us about it? This course was part of activities developed by the subproject of the Institutional Program of Teaching Incentive Scholarship (PIBID) from the Federal University of Goiás (UFG). This subproject aims to discuss and reflect on themes of Psychology with the high school's students. It also presents an approach in the application of psychology in high school. Moreover, it thought to demonstrate how the art utilization as a methodology and didactic resource had a fundamental importance to the psychology teaching to teenagers. Furthermore, it was discussed the importance of reserve a space in the school to talk about life, death, affections and how psychology inserts in that field.
\end{abstract}

Keywords: PIBID; Art; Adolescence; Psychology; Education.

\section{Para citar este artigo:}

BALDUINO, Jordana de Castro; SILVA, Luelí Nogueira Duarte e; MACHADO, Caroline Pereira; TEIXEIRA, Rosana Ferrari Pandim Lisboa. Vida e morte: a educação com arte. Um projeto do PIBID de Psicologia no Ensino Médio. Revista PerCursos, Florianópolis, v. 17, n.35, p. 63 - 82, set./dez. 2016.

\section{DOI: 10.5965/1984724617352016063}

http://dx.doi.org/10.5965/1984724617352016063 
O presente artigo tem como objetivo apresentar uma experiência de docência por meio do subprojeto de Psicologia do PIBID (Programa Institucional de Bolsas de Iniciação à Docência) da Universidade Federal de Goiás. A experiência das autoras ocorreu ao longo do ano de 2015 em uma turma de Ensino Médio de uma escola pública da rede estadual de ensino do Estado de Goiás, como parte de um projeto formativo na disciplina eletiva intitulada “Vida e Morte: o que a arte tem a nos dizer sobre isso?". Tal disciplina visava fomentar discussões acerca de temas angulares da vida humana com apoio nas bases da Psicanálise e da expressão artística.

Não há uma disciplina obrigatória no currículo escolar do ensino médio que seja especificamente de Psicologia, ainda que tal discussão já esteja em pauta desde os anos 1980 (LEITE, 2007). Neste período, historicamente relacionado ao período pós-ditadura militar, se deu um movimento para o retorno de disciplinas de humanidades - Filosofia, Sociologia e Psicologia - no Ensino Médio, intrinsecamente relacionado com o movimento de redemocratização do país. Isso, pois a política educacional oriunda da ditadura e pós-64 retirou grande parte das disciplinas curriculares de Ciências Humanas, uma ação que visava assegurar o controle social, político e ideológico (FREITAS, 1977 apud LEITE, 2007), haja vista o poder de tais disciplinas na formação da consciência crítica e da cidadania.

A partir dos anos de 1980, iniciou-se, então, uma discussão e elaboração de uma proposta do ensino de Psicologia no Ensino Médio, que foi concretizada em 1986 na cidade de São Paulo, na qual foi adotada uma postura ativa e questionadora por parte da Comissão de Ensino designada, levando em conta as críticas de vários setores à Psicologia, acerca do papel dos psicólogos, como as históricas intervenções relacionadas à aplicação de testes para reiterar a ordem vigente e na construção do fracasso escolar, como bem descrito por Patto (1995). A proposta também optava pela discussão de temas e não de correntes teóricas específicas da Psicologia, já que a opção da divisão por vertentes acabaria por não abarcar a problematização esperada, esvaindo o potencial de análise e se transformando em reprodução de disciplinas teóricas dos cursos de Graduação. 
Tal proposta, hoje amplamente empregada em disciplinas de Filosofia e Sociologia no Ensino Médio, funcionam como uma "introdução" a esses campos do saber e tem provocado faíscas de interesse nos alunos. No caso da Psicologia, os temas escolhidos deveriam possibilitar, segundo Leite (2007):

a) os conteúdos teórico-psicológicos abordados deveriam possibilitar uma crítica aos modelos tradicionais, principalmente às concepções biologizantes e naturalizantes dos fenômenos psicológicos. Isto porque estes eram os modelos dominantes e utilizados de forma ideologizada pela Psicologia tradicional, frequentemente assumidos como justificativas para a manutenção do status quo;

b) os conteúdos deveriam permitir uma crítica à ideologia dominante, no caso a ideologia liberal, principalmente no que se refere ao individualismo, como nos ensina Cunha (1977). A razão desta posição centrava-se na compreensão de que, consoante com a concepção liberal, a Psicologia foi tradicionalmente utilizada para reproduzir e justificar a ideia de que a maioria das mazelas humanas é causada por fatores situados dentro do próprio indivíduo, excluindo-se destas análises as condições sociais e institucionais, por exemplo. Pretendia-se, com esta indicação, realizar escolhas que possibilitassem, efetivamente, aos jovens superar as concepções alienadas e alienantes sobre as suas relações com o mundo;

c) os conteúdos deveriam ser abordados respeitando-se a diversidade teórica da Psicologia, ou seja, reconhecia-se que várias correntes teóricas têm contribuições relevantes, de acordo com as expectativas acima colocadas, não devendo, pois, o desenvolvimento dos temas ficar dependente apenas da opção teórica do professor.

Neste sentido, a Comissão de ensino de Psicologia indicou alguns temas, como: a) introdução à Psicologia - caracterização da Psicologia, do psicólogo e da área de atuação; b) a adolescência - desmistificação do período, importância das relações sociais e mudanças em sua concepção de acordo com cultura, momento histórico e classe social; c) neutralidade científica - ideologia, uso da ciência e a quem ela serve e pode servir; d) comportamentos herdados e aprendidos - problematização do papel genético e do papel do meio na formação do homem, bem como inteligência, linguagem, entre outros; e) “normal” e "anormal” - discussão acerca da patologização, do papel da cultura, rótulos e estigmas sociais; f) motivação humana - determinantes intrínsecos e extrínsecos a escolhas e relações; g) alienação; h) comunicação - tanto no meio social quanto papel dos 
meios de comunicação de massa; i) emoção e afetividade; j) agressividade; I) trabalho e profissão (LEITE, 2007).

Com a mudança dos responsáveis pelos órgãos da Secretaria de Educação de São Paulo, a política relacionada às disciplinas de Ciências Humanas não obteve continuidade, assim como outras propostas e intervenções que foram enxugadas. Porém, as disciplinas de Filosofia e Sociologia prosseguiram no currículo, enquanto que os temas da Psicologia permaneceram apenas como transversais.

Entretanto, por mais que não exista uma matéria específica de Psicologia, é possível perceber, cada vez mais, como ela se faz presente na educação, de modo geral, e no Ensino Médio, em particular. Pode-se, atualmente, verificar a presença da Psicologia, por exemplo, quando se observa projetos de disciplinas em escolas de tempo integral, como o Projeto de Vida, do Programa "Novo Futuro", da rede estadual do Estado de Goiás e a Escola da Inteligência ${ }^{3}$ de Augusto Cury, com apostilas impregnadas de conteúdos, temas, categorias e conceitos psicológicos. Além de diversas outras intervenções realizadas nas escolas que envolvem conhecimentos psicológicos como recompensas, punições e prêmios.

Chama atenção, entretanto, o fato destes projetos, disciplinas, conteúdos, práticas serem, na maioria das vezes, trabalhados e desenvolvidos não por psicólogos, mas por professores ou profissionais de outras áreas e, por vezes, até mesmo por psicólogos que tratam de maneira preconceituosa e mantenedora do status quo determinados temas. Isso se torna fonte de diversos problemas, como o ensino “equivocado" de temas relevantes à vida social e psíquica, ao homem e à sociedade,

\footnotetext{
${ }^{2} \mathrm{O}$ "Projeto de Vida" é a parte mais importante do projeto "Novo Futuro" e se configura como uma espécie de acompanhamento vocacional. Entretanto, ele é constituído de apostilas prontas a serem ministradas por profissionais não necessariamente formados em Psicologia, o que se torna um problema ao pensar que eles estariam lidando com conteúdos específicos deste ramo da ciência. SEDUC. Construção do "Projeto de Vida" é um dos diferenciais do programa "Novo Futuro". Disponível em: <http://www.seduc.go.gov.br/imprensa/?Noticia=3812>. Acesso em: 10 de mai. 2016.

${ }^{3}$ A Escola da Inteligência é um programa educacional desenvolvido pelo autor de autoajuda Augusto Cury que é aplicado durante uma hora por semana dentro da grade curricular, como uma nova disciplina ou dentro de uma já existente. Ele propõe "educar" as emoções e reduzir a indisciplina, por exemplo, sendo tais objetivos reiteradores das práticas neoliberais na educação e responsabilizadores do indivíduo pelo fracasso, o que vai contra uma proposta emancipatória e crítica da educação. ESCOLA DA INTELIGÊNCIA. Disponível em: <http://www.escoladainteligencia.com.br . Acesso em: 10 de mai. 2016.
} 
reforçando o senso-comum e, portanto, naturalizando estereótipos e preconceitos, além de minimizar o potencial educador e emancipatório da Psicologia.

A licenciatura em Psicologia na UFG, associada ao Programa Institucional de Bolsas de Iniciação à Docência (PIBID), tem contribuído não apenas para discutir as possibilidades e limites da Psicologia na sua interface com a educação, como também para criar espaços de intervenção, em que se concretiza e se desenvolve o pensar, o planejar e o executar disciplinas que abordam temas e conteúdos da Psicologia para alunos do Ensino Médio. Além dessa possibilidade de formação crítica para os alunos, também se possibilitou uma formação que ultrapassou a teoria ministrada no curso de Psicologia. Através dessa experiência, os bolsistas puderam ter uma vivência que se constituiu enquanto crítica e humana, no que tange a real apropriação e estudo dos conteúdos histórico-socialmente determinados que foram explorados, a participação na realidade própria e dos alunos e a possibilidade de ação enquanto transformadores da realidade.

\section{O PIBID de Psicologia}

O PIBID é uma iniciativa da Capes para a valorização da formação dos professores, visando à melhoria da qualidade do ensino básico, direcionado às Instituições de Ensino Superior (públicas, comunitárias, confessionais e filantrópicas sem fins lucrativos) que oferecem cursos de licenciatura, e que devem elaborar um projeto de iniciação à docência realizado em parceria com escolas da rede pública de ensino. Esse programa tem por objetivo proporcionar o desenvolvimento e aprofundamento das competências e habilidades dos graduandos em licenciatura, através da integração entre Educação Superior e Educação Básica e da articulação teórico-prática através da experiência docente na realidade da escola pública.

O subprojeto de Psicologia, campus Goiânia, se soma ao projeto institucional da UFG em agosto de 2012, apenas com uma escola parceira, um orientador e supervisor e seis bolsistas. Porém, esse número é ampliando em 2014 com a abertura do edital n. 102/2013, contando até os dias atuais com 21 bolsistas de iniciação à docência, quatro 
supervisores de campo, dois orientadores e duas escolas parceiras. O objetivo principal do projeto é desenvolver ações que propiciem a atuação do licenciando em Psicologia em uma Escola do Ensino Médio, a fim de contribuir para uma formação humana emancipatória que permita uma visão crítica da realidade.

O início das atividades do subprojeto de Psicologia, regional Goiânia, ocorre com a ida dos bolsistas a campo para observação e levantamento de dados para, posteriormente, serem desenvolvidas as propostas de intervenção. Deste modo, foram realizados no ano de 2015 quatro projetos de intervenções em duas escolas públicas estaduais de ensino médio. Um dos projetos foi desenvolvido em uma instituição aos sábados, se configurando como disciplina/oficina optativa. Os outros três projetos realizaram-se na outra instituição parceira, sendo desenvolvidos em três disciplinas, uma denominada "Projeto de vida" e as outras eram disciplinas eletivas, as quais estavam inseridas no currículo da respectiva escola que se configura pelo funcionamento em tempo integral. Segundo as especificidades de cada instituição de ensino, os projetos implementados tiveram características e estruturações distintas. No entanto, todos os temas e conteúdos eram ministrados e desenvolvidos de uma maneira coerente com a concepção de Psicologia do Projeto Político Pedagógico da UFG. Nele, a formação integral do aluno acontece quando há um contato e oportunidade de atuação "em diferentes contextos considerando as necessidades sociais, os direitos humanos, tendo em vista a promoção da qualidade de vida dos indivíduos, grupos, organizações e comunidades" (UFG, 2007). Portanto, tal projeto é uma ação para que a comunidade na qual esta instituição se faz presente se comunique e também se beneficie com ela.

Como mencionado, o presente texto pretende apresentar o projeto de disciplina desenvolvido no ano de 2015 e que tinha como objetivo central discutir temas relacionados à vida e à morte, do qual as autoras fizeram parte. O projeto foi desenvolvido na Escola $X$ da rede estadual de ensino do Estado de Goiás, uma escola integral que oferta, para além das disciplinas obrigatórias, disciplinas eletivas dos mais variados temas. A disciplina em voga, denominada "Vida e Morte: o que a arte tem a nos dizer sobre isso?" foi proposta pela supervisora/professora de Filosofia e desenvolvida 
em conjunto com as autoras e professora/orientadora em uma turma composta por cerca de trinta e cinco alunos, do primeiro ao terceiro ano do Ensino Médio da escola.

\section{Fundamentação teórica da disciplina}

É frequente o uso do termo "vida" para se fazer referência a momentos clássicos como o nascimento de um bebê ou o uso do termo "morte" quando estritamente ligado à morte física, ou seja, com o cessar da vida. Mas, tratar a vida e a morte como extremos distantes é limitar as possibilidades de questionamentos pertinentes à existência. Desse modo, é tentando evitar posturas reducionistas que permeiam a vida, que nos apropriamos da psicanálise e das visões de homem da filosofia. Passando, assim, a compreender a tensão entre a vida e a morte sob uma nova ótica.

Freud (1920[1996, p. 161]), para quem “o objetivo da vida é a morte, e remontando ao passado: o inanimado já existia antes do vivo", tem a compreensão de vida e morte como altamente complementares. Essa construção, por sua vez, pode ser melhor explicada utilizando a teoria das pulsões. Com base em Freud (1915[2004]), a pulsão constitui-se enquanto uma energia que tem a ação de uma força interior constante com a intenção de satisfazer uma necessidade. Ocorre que, não só uma, mas várias forças agem ao mesmo tempo no sujeito e, assim, podem acabar entrando em conflito.

Os processos que dão origem às pulsões são, para Freud, inconscientes e obedecem ao princípio de prazer-desprazer, em que "tais processos aspiram à obtenção de prazer. Dos atos que possam provocar desprazer a atividade psíquica se recolhe" (FREUD, 1911[2004, p. 65]). Isso significa dizer que existe uma tendência a ser seguida pelo sujeito de evitar experiências desprazerosas, ainda que isso implique no adiamento do prazer.

Além disso, Freud (1905 apud LEITE, 2011, p. 41) em “Três ensaios sobre a teoria da sexualidade" aponta para o fato da vida humana ser marcada por perdas desde o nascimento até o fim da vida. Para ele, o sujeito experimenta um desamparo tal como a fase de desmame, por exemplo, e que sua existência será sempre atravessada pela falta 
de um objeto que o complete de maneira plena. Daí, a vivência da angústia, de um medo do desprazeroso desamparo que um dia foi experienciado.

Dessa forma, após alguns anos de estudos, Freud constrói a teoria de que existiriam as pulsões de vida e de morte. As de vida teriam a finalidade de preservar o organismo vivo e sua espécie. Já a pulsão de morte possuiria a tendência de levar o sujeito a retornar ao estado inorgânico a fim de cessar, por completo, as tensões geradas. Além disso, uma pulsão não atuaria de maneira isolada em relação à outra - apesar de parecerem contraditórias, elas se complementariam. O sujeito de fato chega à morte, mas a pulsão de vida o preservaria e atuaria para que, preferencialmente, ele pudesse fazer isso a seu próprio modo.

Todavia, a finitude das coisas e pessoas tem sido tratada das mais diversas formas com o passar dos séculos. O “dia dos mortos”, no México, é uma celebração para os mortos que visitariam os seus familiares nesse dia. De maneira semelhante, os japoneses budistas também retornam às suas cidades natais para receber os familiares que já faleceram. Trata-se do festival chamado "Bon Odori”. Tais representações só se tornam possíveis devido ao fato do ser humano, diferentemente do animal, utilizar-se da linguagem como forma de estar no mundo. Com isso, a cada nova perda que surgir ao longo de sua vida, o sujeito será capaz de simbolizá-la e ressignificá-la de diferentes formas.

Mas a riqueza maior talvez não se encontre no fato de que há a linguagem propriamente dita e sim, pela existência de linguagens tão múltiplas que permitam ao homem escolher, a seu próprio modo, uma forma específica de estar no mundo. Isso explica a grande variedade de representações sobre a morte, por exemplo. Sobre isso, Freud (1930[1996]), em “O mal-estar da civilização”, afirmou ser a arte uma satisfação substitutiva que ajudaria o sujeito a suportar a própria existência e os sofrimentos nela inclusos.

Foi refletindo e pensando na tensão entre vida e morte, tal como concebida por Freud, que consideramos a importância de colocar à disposição dos alunos do ensino médio uma gama de expressões artísticas, por meio das quais eles poderiam se identificar 
com os artistas e autores selecionados, o que lhes daria a oportunidade de elaborar suas perdas, afetos e conflitos. Para Kon (2001), em “Entre a psicanálise e a arte”, a arte possibilita ao sujeito a criação de um mundo próprio e também um rearranjo possível da realidade de modo que a fantasia entre em cena. Sobre esse fazer artístico, Freud (1925, 1924 apud KON, 2001) em “Um estudo autobiográfico”, afirma que

O artista, como o neurótico, se afastara de uma realidade insatisfatória para esse mundo da imaginação; mas, diferentemente do neurótico, sabia encontrar o caminho de volta daquela e mais uma vez conseguir um firme apoio na realidade. Suas criações, obras de arte, eram as satisfações imaginárias de desejos inconscientes, da mesma forma que os sonhos; e, como estes, eram da natureza de conciliações, visto que também eram forçados a evitar qualquer conflito aberto com as forças de repressão.

Considerando as possibilidades de criação artística enquanto metodologia, Biazus e Cezne (2010) afirmam que a criação é uma possibilidade de defesa do sujeito em relação à pulsão de morte e que se relaciona ao trauma. Isso porque o trauma diz respeito a uma situação que deixa marcas e que trata de um excesso pulsional que permanece no sujeito enquanto violência, enquanto intraduzível e que, assim, não consegue ser representado simbolicamente pelo sujeito.

Ele, então, se encontra em uma posição de passividade em relação a tão indefensável excesso pulsional, com instrumentos de simbolização insuficientes, fazendo com que ele caia em um abissal desamparo envolto pela maior irrupção da pulsão de morte (MORAIS, 2006 e BIRMAN, 2002 apud BIAZUS; CEZNE, 2010). Esse estado é responsável pela necessidade humana de criar, já que esse conteúdo que não produz sentido e que escapa à representação pode-se fazer presente no criar, já que neste momento o sujeito tem possibilidade de "dominar" a pulsão sem fechar o seu sentido como seria feito na criação técnico-científica, por exemplo. Isso pois, na criação artística, a criação não tem um sentido fechado, mas, pelo contrário, se caracteriza por sua abertura de sentidos, convidando o Outro a interpretá-la e, assim, criar continuamente. De acordo com Sousa (2002 apud BIAZUS; CEZNE, 2010): “a arte toca a fantasia de todos 
e convoca o espectador na função de intérprete e leitor do mundo. Ela se propõe propositalmente aberta, a fim de apreender o Outro como parte constituinte do seu processo." Cavalcanti (2010, p. 22) reitera a importância da arte para a constituição do sujeito a partir da lógica concebida por Nietzsche que "vê a arte como uma manifestação da vontade de potência, com exaltação do sentimento de vida, que transborda para o mundo das imagens e do desejo".

A arte enquanto uma forma de "ler" o mundo é justamente o mote central da disciplina, e, apresentou-se como finalidade de todos os esforços conferidos nos planejamentos e execução das aulas. Uma vez que "as artes ensinam os alunos a agir e a julgar na ausência de regras, a confiar nos sentimentos, a prestar atenção a nuances, a agir e a apreciar as consequências das escolhas, a revê-las e, depois, fazer outras escolhas" (EISNER, 2008, p. 8). Portanto, o educar por intermédio da arte revela-se como possibilidade outra, como alternativa ao que as palavras não conseguem dizer, o que pode ampliar a capacidade crítica dos estudantes envolvidos. Sobre o exposto, Duarte (1988, p. 43) esclarece que

a linguagem procura sempre captar os nossos sentimentos, significandoos e classificando-os em conceitos. Porém, feito apanhar um punhado de areia, sempre lhe escapa algo por entre os dedos. A linguagem, que é conceitual e classificatória, apenas aponta e classifica este sentir, sem, contudo, poder descrevê-lo.

O autor conclui, então, que a arte surge da falta de algo que apresente integralmente os sentimentos experienciados. Para ele, o artista seria aquele que “procura concretizar, nas formas, aquilo que é inefável, inexprimível pela linguagem conceitual” (DUARTE, 1988, p. 45). A disciplina ousou, portanto, lançar o desafio de que os alunos experimentassem o lugar de artistas de suas vivências diárias.

Mas, por que falar sobre tudo isso com adolescentes do Ensino Médio? Contardo Calligaris (2009), um importante teórico da Psicanálise, entende a adolescência como um período de "moratória" em que após alguns anos de preparação física e psíquica para 
serem reconhecidos como adultos, os adolescentes são informados que ainda precisarão estar mais algum tempo sob a tutela dos adultos, assim permanecendo até que atinjam uma determinada "maturidade". Ocorre que este período parece interminável e a busca pela dita "maturidade" parece incansável, podendo causar grande angústia nesses adolescentes.

É pensando nessa realidade de "moratória" dos adolescentes na contemporaneidade que o projeto em questão se propôs trabalhar temas referentes à vida e à morte de modo a causar uma reflexão entre eles que fosse significativa e que lhes permitissem compreender e elaborar as perdas, as angústias e os conflitos na passagem para a vida adulta. Desse modo, buscou-se amenizar o sofrimento causado pelas dúvidas a respeito das paixões e vícios humanos, por exemplo.

Isso, sem deixar de fazer interlocução com os aspectos sociais e filosóficos de cada elemento trabalhado, visando somar o aprendizado dos alunos a respeito da dualidade interno-externo e sobre os aspectos de seu funcionamento interdependente. Por isso, este projeto tenta dar algum amparo para que os adolescentes tenham recursos e um pouco mais de preparo para lidar com as diversas perdas e conflitos que possam vir a surgir ao longo de suas vidas.

Para além dos benefícios almejados aos alunos, pretendeu-se, também, causar um impacto sobre a comunidade, já que esses alunos poderão criar e viver relações e vínculos de forma mais reflexiva e crítica, possibilitando uma compreensão maior dos eventos da vida e do seu papel no mundo.

Pensa-se, também, que há inúmeros benefícios na vida acadêmica dos bolsistas (os professores desse projeto): a presença e o contato real com o ambiente de sala de aula fornecem experiências ímpares ao futuro professor, possibilitando uma vivência a mais para a sua formação e um saber acerca de elementos teórico-práticos da educação.

As trocas com os alunos e com o professor supervisor são também extremamente férteis, pois contribuem para a formação de todos, em especial dos bolsistas, que aprendem com as demandas, participações e vínculo com os alunos. Em relação ao professor supervisor, este se beneficia por ter a possibilidade de agregar os 
conhecimentos psicológicos a sua área de estudo e ampliar e rever sua forma de conceber a docência. Outro benefício seria, ainda, o incentivo à inserção do licenciando no campo da Educação a partir das vivências e da produção de material didático e de artigos científicos.

Por fim, o projeto também pode trazer ganhos à Psicologia em si, já que fornece material e reflexões relevantes para o desenvolvimento de estudos e pesquisas, além de questionar seus temas e construtos, gerando um pensamento crítico, colocando suas teorias em uma perspectiva contemporânea, compreendendo como se dão as configurações dos temas nos dias de hoje, contribuindo cada vez mais para uma compreensão teórica e prática do campo da Psicologia.

\section{A Arte como amálgama entre a Psicologia e a Filosofia na Educação}

As aulas eram ministradas semanalmente pelas bolsistas e pela supervisora/professora de Filosofia, o que permitia uma aproximação e diálogos extremamente ricos entre as duas áreas do saber. Por meio do diálogo e do estímulo à discussão em grupos, abria-se espaço para que os alunos refletissem sobre os temas propostos.

Eram expostos conteúdos teóricos tanto de Psicologia quanto de Filosofia, sempre ilustrados e enriquecidos por reflexões e intercâmbios com formas de expressão artística, tais como a pintura, a literatura, a música, o cinema, o teatro, os documentários e as ilustrações.

Adotou-se como metodologia o debate livre de ideias, a partir de temas previamente escolhidos pelos alunos, pelas bolsistas ou pela professora supervisora, peças artísticas e um caderno para registro da experiência em sala, em que se podia tanto escrever ou desenhar, como uma forma de expressão artística de cada um.

Os objetivos da disciplina eram: viabilizar aos alunos a compreensão do ser humano enquanto provido de linguagem; refletir e desmistificar temas que normalmente não são abordados na escola - como vida, morte e paixões - e que, portanto, poderiam ser fontes de conflitos; exibir e discutir expressões artísticas que pudessem enriquecer as experiências dos alunos e oportunizar possíveis identificações com os artistas 
apresentados para que os estudantes também se sentissem contemplados em relação aos conflitos inerentes à existência; expor produções filosóficas e psicológicas com visão crítica e diferenciada, de forma a ampliar a formação e visão dos alunos; levar os alunos a também experimentarem vários modos de expressão de seus sentimentos por meio da produção artística; construir um ambiente receptivo e confortável aos alunos para que eles conseguissem estabelecer vínculos entre eles - tendo em vista que a sala de aula também é um modo de vivência social - e ampliar sua visão e formação e acrescentar, às próprias autoras, experiência, vivência e conhecimentos didático-pedagógicos, bem como a reflexão, o estudo e uma maior apropriação da teoria.

As primeiras aulas foram direcionadas à introdução da Psicologia de fato, explicando alguns de seus conceitos básicos, diferenciando-a do senso comum e desmistificando concepções biologicistas e limitadoras da subjetividade e do comportamento humano. Depois disso, a escolha dos temas foi feita seguindo uma lógica que, em vez de conceber a realidade como dualista e maniqueísta, pudesse demonstrar a complexidade e ambiguidade das emoções, de acordo com a teoria das pulsões de Freud. Assim, ao escolher um tema, eram expostas peças artísticas que tratassem do mesmo e, sutilmente, era feita uma construção de pensamento, juntamente com os alunos, que levasse a uma discussão de como o sentimento em si é ambíguo.

Para que tal ideia se tornasse mais clara aos alunos, utilizou-se a análise das diferenças entre as éticas platônica e aristotélica, bem como as visões fundantes a respeito das paixões segundo Platão e Nietzsche. Foi explorado, por exemplo, que enquanto para Platão, o homem deve ser capaz do controle das próprias paixões para a preservação da racionalidade, Nietzsche propõe a ideia do homem livre da moral e de que as paixões seriam a força propulsora para isso. Carvalho (2012, p. 2002) colabora para a compreensão das filosofias de base platônica ao afirmar que delas se fundam "uma tradição em que somente o que é necessário tem validade e verdade". Enquanto para grande parte dos filósofos gregos "tudo deveria passar pelo crivo da razão, inclusive as nossas paixões", Nietzsche "queria uma afirmação da vida, um retorno à natureza, um amor ao próprio destino que a tragédia grega valorizava e que havia ficado para trás com o racionalismo desde Sócrates, Platão e Aristóteles" (CAVALCANTI, 2010, p. 85). 
O passeio pelas ideias de tais filósofos acabou por dar base ao pensamento freudiano a respeito, também, das paixões. A atmosfera criada em sala de aula configurou-se a partir de uma espécie de diálogo atemporal entre os teóricos em questão. Para os alunos, tornou-se cada vez mais clara a interconexão entre um pensamento e outro. Tornou acessível o estabelecimento de relações entre a antiguidade grega e o mundo contemporâneo, o que gerou uma maior fluidez nas atividades de produções artísticas propostas em sala de aula.

Nesse sentido, a filosofia em constante comunicação com a psicologia revelou-se enquanto uma importante ferramenta para a compreensão da importância de se conhecer o desenvolvimento do pensamento ao longo da história, o que acaba por contribuir também para o exercício de cada um deles em sempre situarem fatos, experiências e situações no contexto sócio histórico específico no qual se inserem.

O teatro também ganhou espaço em sala de aula para melhor apreensão do tema "paixões" a partir da encenação do mito de Medéia, de Eurípedes. Assim, primeiro foi apresentada a história de Jasão e Medéia contando que os deuses envolvidos fossem devidamente mencionados. A tragédia grega traz questões relevantes a respeito de relacionamentos amorosos, infanticídio e em como amor e ódio são dois lados de uma mesma face, complementares. Diante de tantos elementos, escolhemos por manter o foco das discussões em temas concernentes a relacionamentos amorosos, de modo que foi possível estabelecer uma ponte com a recorrência dos estabelecimentos de relacionamentos abusivos em nossa sociedade.

Dessa forma, expúnhamos e debatíamos obras que demonstravam como tal paixão estava não só ligada às pulsões de vida, mas, também, às de morte. Isso permitia que fizéssemos ligações com vários temas do cotidiano, notícias, situações comuns à vida do adolescente, conflitos que perpassam o homem, dilemas da sociedade contemporânea e como todos estes aspectos estão representados na arte e encontram alguma base na Psicanálise. Assim, os debates eram sempre bastante calorosos, e as atividades propostas faziam com que alunos de diferentes turmas, idades, posições e contextos pudessem dialogar e crescer com a troca de opiniões. 
Alguns dias após os debates, pedíamos para que os alunos expressassem o que sentiam e os pensamentos construídos acerca dos temas abordados no caderno destinado à matéria. Também era aberto um espaço em algumas aulas para que isso fosse feito em grupo ou individualmente. Percebeu-se, neste processo, que os alunos sempre participavam de alguma forma, sendo presentes nos debates e/ou desenvolvendo as atividades artísticas. Alguns se expressavam ricamente nas discussões em grupo e preferiam não desenvolver no caderno, enquanto outros desenvolviam longas páginas no mesmo e preferiam se manter calados durante os debates. Também se viu que, para alguns, o caderno extrapolou suas funções relacionadas à disciplina, servindo como um instrumento para que registrassem também textos, crônicas, ideias, desenhos e músicas sobre seu cotidiano. Alguns alunos iniciaram a disciplina muito tímidos e percebeu-se uma participação crescente deles ao longo das aulas, bem como uma formação de fortes vínculos com os colegas da disciplina.

Ao final da disciplina eletiva foram feitas avaliações com a turma oralmente e de forma escrita. Foram questionados sobre o que os atraiu para que se matriculassem na disciplina, os temas que mais foram relevantes a eles, a maneira de que gostaram mais de trabalhar os assuntos, o que mais e menos gostaram no geral e um espaço para críticas, sugestões e comentários. De forma geral, os alunos descreveram a disciplina como um momento prazeroso no qual podiam se expressar e que a eletiva tinha um caráter diferenciado das outras matérias por conta disso. A presença na eletiva, em parte, era justificada pelo interesse nos temas abordados ou pelo afeto à professora da escola. Quando indagados acerca dos aspectos que mais os agradaram, foram frequentes respostas que exaltavam a abertura para a produção de material artístico e para a discussão, e a utilização destes para uma avaliação contínua em vez dos métodos de avaliação tradicional.

\section{Considerações finais}

É importante ressaltar a especificidade da licenciatura em Psicologia, qual seja, não termos uma disciplina no ensino básico. Esse fator, por um lado, dificulta encontrar um campo definido de atuação na escola, porém, por outro lado, nos possibilita conhecer 
com maior profundidade a escola e analisar suas necessidades e demandas para pensar uma atuação e uma intervenção junto a sua comunidade. Fez-se relevante, também, a compreensão da atual configuração das leis de ensino que pudessem fornecer brechas por entre as quais se pode inserir um ensino não somente voltado para a aprovação no vestibular e subsequente inserção no mundo do trabalho, contribuindo ainda mais para o modelo capitalista e neoliberal de ensino, mas para a formação de cidadãos verdadeiramente críticos e capazes de alterar a realidade tanto a partir de conhecimentos e conteúdos históricos e socialmente configurados como necessários, mas também pela compreensão de seu papel na sociedade e valorização de sua experiência, cultura e valores próprios. Neste sentido, a Psicologia pode e, muito, contribui para a emancipação do sujeito a partir de disciplinas que abordem seus conteúdos específicos e que possam causar reflexão e criticidade, considerando que a mesma estuda o homem em sua totalidade, incluindo suas relações com a sociedade.

Isso permitiu que o projeto das autoras fosse realizado junto ao PIBID, já que o tema central do mesmo foi escolhido a partir das demandas específicas da uma escola de nível médio na cidade, juntamente aos conflitos já conhecidos pela Psicologia e que são comuns aos alunos adolescentes e ao homem no geral. Além disso, esse fator nos oferece uma liberdade em sala de aula que só poderá enriquecer o aprendizado de todos os envolvidos, possibilitando a elucidação do que seria um ensino que não fosse dividido por matérias, mas que dialogassem entre si de tal forma que não fosse necessária tal formatação, muitas vezes, reducionista de mundo.

O planejamento da disciplina se deu de tal forma que se tornou impossível não estudar para além dos conteúdos com os quais havíamos entrado em contato pela grade curricular do curso de psicologia. Assim, nos deparamos com questões que nem ao menos sabíamos que tínhamos. Por exemplo, o porquê de a arte ser tão citada nos trabalhos de Freud, e pudemos identificar a resposta pela observação e escuta de nossos alunos em como cada um foi capaz de elaborar sobre a sua existência com base na arte. Este fato corrobora, ainda, para nos lembrar do quão acertada foi a escolha da metodologia, uma vez que levou ao êxito os objetivos iniciais de que os afetos pudessem ser trabalhados no contexto escolar. 
Percebeu-se também a importância do referencial psicanalítico como aporte teórico norteador da disciplina e como suporte para criar as condições de expressão dos alunos. O conhecimento psicanalítico, usualmente voltado ao âmbito clínico, ganha uma nova dimensão ainda mais emancipatória quando trabalhado no contexto educacional, permitindo a sua contundente e constante releitura e a ampliação de seus conceitos para novas realidades e para a contemporaneidade.

O projeto também traz ganhos à Psicologia em si, já que fornece material e reflexões relevantes para o desenvolvimento de estudos e pesquisas, além de questionar seus temas e construtos, gerando um pensamento crítico, compreendendo como se dão as configurações dos temas nos dias de hoje, contribuindo cada vez mais para uma compreensão teórica e prática do campo da Psicologia.

Por último, a experiência do exercício da docência possibilitada pelo subprojeto de Psicologia do PIBID permitiu, por um lado, a ampliação da formação do bacharel psicólogo, e, por outro, a consolidação de uma formação pedagógica e teórica em psicologia. A experiência, enfim, contribuiu para a formação de um psicólogo mais crítico, voltado para a busca de uma intervenção emancipatória, com vista à construção de um mundo mais humano e justo para todos.

\section{Referências}

BIAZUS, Camila B.; CEZNE, Graziela O. M. Expressões do Inacabado: encontros entre psicanálise e arte. Psicanálise \& Barroco, v.8, n.2, 2010, p. 49-73.

CALLIGARIS, Contardo. A adolescência. São Paulo: Publifolha, 2009.

CARVALHO, Alonso B. Razão e paixão: necessidade e contingência na construção da vida ética. Conjectura, Caxias do Sul, v. 17, n. 1, 2012.

CAVALCANTI, Cristina Aparecida T. Psicanálise e Nietzsche: um estudo das paixões e da crítica à racionalidade à luz da psicanálise e da filosofia. 2010. 92f. Dissertação (Mestrado Profissional em Psicanálise, Saúde e Sociedade) - Universidade Veiga de Almeida, Rio de Janeiro, 2010.

DUARTE, João Francisco J. Por que arte-educação? Campinas, SP: Papirus, 1988. 
EISNER, Elliot E. O que pode a educação aprender das artes sobre a prática da educação? Currículo sem fronteiras, v. 8, n. 2, 2008.

FREUD, Sigmund. (1911) Formulações sobre os dois princípios do acontecer psíquico. In: FREUD, S. Obras Psicológicas completas de Sigmund Freud: v. 1. Rio de Janeiro: Imago, 2004.

FREUD, Sigmund. (1915) Pulsões e os destinos da pulsão. In: FREUD, S. Obras psicológicas completas de Sigmund Freud: v. 1. Rio de Janeiro: Imago, 2004.

FREUD, Sigmund. (1920) Além do princípio do prazer. In: FREUD, S. Obras psicológicas completas de Sigmund Freud. Ed. Standard Brasileira, vol. XVIII. Rio de Janeiro: Imago, 1996.

FREUD, Sigmund. (1930) O mal-estar na civilização. In: Edição Standard Brasileira das Obras Psicológicas Completas de Sigmund Freud. [Tradução de J. Salomão]. Rio de Janeiro: Imago. 1996. v. 21, p. 65-148.

KON, Noemi M. Entre a psicanálise e a arte. In: SOUSA, E. A. L., TESSLER, E., SLAVUTZKY, A. (Orgs.). A invenção da vida, arte e psicanálise. Porto Alegre: Ed. Artes e Ofícios, 2001.

LEITE, Sônia. Angústia. Rio de Janeiro: Editora Zahar, 2011.

LEITE, Sônia. A. da S. Psicologia no ensino médio: desafios e perspectivas. Temas Psicol., Ribeirão Preto, v. 15, n. 1, 2007.

PATTO, Maria Helena Souza. A produção do fracasso escolar. São Paulo: T.A. Queiroz Editor, 1993.

SOLIGO, Ângela; AZZI, Roberta. Psicologia no Ensino Médio. In: CONSELHO FEDERAL DE PSICOLOGIA. Seminário nacional do ano da educação psicologia: profissão na construção da educação para todos. Brasília: Conselho Federal de Psicologia, 2009, p. 55-64.

UNIVERSIDADE FEDERAL DE GOIÁS. Projeto Pedagógico do curso de graduação em Psicologia. Goiânia: UFG, 2007. 
Recebido em: 28/07/2016 